\title{
Systems, habitats or places? Evaluating the potential role of landscape character assessment in operationalising the ecosystem approach
}

DOI:

10.1080/01426397.2017.1415314

\section{Document Version}

Accepted author manuscript

Link to publication record in Manchester Research Explorer

Citation for published version (APA):

Morrison, R., Barker, A., \& Handley, J. (2018). Systems, habitats or places? Evaluating the potential role of landscape character assessment in operationalising the ecosystem approach. Landscape Research. https://doi.org/10.1080/01426397.2017.1415314

\section{Published in:}

Landscape Research

\section{Citing this paper}

Please note that where the full-text provided on Manchester Research Explorer is the Author Accepted Manuscript or Proof version this may differ from the final Published version. If citing, it is advised that you check and use the publisher's definitive version.

\section{General rights}

Copyright and moral rights for the publications made accessible in the Research Explorer are retained by the authors and/or other copyright owners and it is a condition of accessing publications that users recognise and abide by the legal requirements associated with these rights.

\section{Takedown policy}

If you believe that this document breaches copyright please refer to the University of Manchester's Takedown Procedures [http://man.ac.uk/04Y6Bo] or contact uml.scholarlycommunications@manchester.ac.uk providing relevant details, so we can investigate your claim.

\section{OPEN ACCESS}


Systems, Habitats or Places:

Evaluating the potential role of landscape character assessment in operationalising the ecosystem approach

\section{Authors:}

Rachel Morrison (corresponding author), Planning and Environmental Policy, University College Dublin; Studio 54, Richview Building, Bellfield Campus, Dublin 4, rachel.morrison@ucd.ie, +35317162678.

John Handley, Planning and Environmental Management, University of Manchester; Arthur Lewis Building, Oxford Road, M13 9PL, john.handley@manchester.ac.uk, +44 1625 526527.

Adam Barker, Planning and Environmental Management, University of Manchester, Arthur Lewis Building, Oxford Road, M13 9PL, adam.barker@manchester.ac.uk, +44 161 2756889.

Accepted for publication in the Journal of Landscape Research August $4^{\text {th }} 2017$. 
Evaluating the potential role of landscape character assessment in operationalising the ecosystem approach

\section{Abstract:}

A key challenge for research and practice is to understand how the ecosystem approach can be rolled out in spatial planning, management and decision-making. Any framework used to apply the ecosystem approach needs to not only be environmentally coherent but also socially meaningful. Drawing on semi-structured interviews and case studies, this paper examines the potential role of one place-based approach, landscape character assessment, as a medium to ensure socio-ecological relevance in operationalising the ecosystem approach. Our findings that although place-based approaches have value as frameworks for distilling the ecosystem approach into a manageable form, their ecological relevance is a subject of debate. However, the potential relationship between landscape character, function, and ecosystem services presented a powerful pathway for operationalising the ecosystem approach. The ecosystem approach may, in turn, complement landscape character assessment by providing a framework for exploring the functional dimension of landscape condition.

Key words: Landscape Character Assessment, Ecosystem Approach, Ecosystem Services, Place-Based Assessments. 


\section{Introduction: Operationalising the Ecosystem Approach}

Since its introduction, by the Convention on Biological Diversity (CBD) in 1995, adopting an ecosystem approach (Fig.1) has been mainstreamed in international and national environmental policy, and promoted as the new ecological solution to complex global environmental problems (e.g. Secretariat of the CBD, 2004; Daily and Matson, 2008). Taking an ecosystem approach effectively means opting:

To plan, develop and manage our environments in a manner that addresses the multiple needs and desires of societies without jeopardizing ecological limits and functions for the benefits of providing ecosystems services to future generations (Secretariat of the CBD, 2000:104).

By integrating ecological principles into planning and decision-making, the ecosystem approach aims to link social and ecological perspectives to achieve a joined-up approach to environmental and natural resource management and place the maintenance of ecosystem services at the centre of decisions making (see Fig. 2 for a full glossary of terms used in this paper).

\section{[Figure 1 Should be inserted near here]}

\section{[Figure 2 Should be inserted near here]}

While adopting the ecosystem approach is considered an important paradigm shift for the achievement of long-term ecological sustainability (Hartje et al 2003), it is also extremely challenging in practice due to the significant disconnect between the current system of planning and decision making in the UK and ecological principles (Holt et al. 2011). For current practice, the ecosystem approach demands an ambitious paradigm shift in natural resource management (Hartje et al. 2003; Holt et al. 2011), to bring together disparate silos 
of planning and management, sectorial organisation and institutional structures under a holistic trans-disciplinary framework (Smith and Maltby, 2003; Potschin et al. 2011).

Current practice, and the scale and boundaries it operates at, seems ill-equipped to encompass both natural and social systems (Cummings et al. 2006). Ecosystems are dynamic, linked to habitats configurations, population distributions and ranges, and systems rather than bureaucratic borders (De Leo and Levin, 1997). Hancock (2010:194) highlights an inherent 'mismatch between the scale and boundaries at which ecological and human systems are organised, when governing at the interface between the two'. These spatial and institutional disconnects are widely acknowledged, and have led to questions as to whether existing frameworks can facilitate the ecosystem approach, or if new frameworks need to be designed (Holt et al. 2011; RSPB, 2009; Maltby, 2000; Haines-Young and Potschin, 2007). Determining how the ecosystem approach can be rolled out on a national scale and translated into a widely accepted, accountable and democratic planning and negotiating process, is a key challenge for policy and practice.

In the UK context, efforts to operationalise the ecosystem approach were initially slow to materialise (Daily et al. 2009; De Groot, 2010), reflecting questions around feasibility and implementation challenges (Hartje et al. 2003). However, over the last few years the ecosystem approach and ecosystem services have begun to gain momentum and practical application. On a policy level, Holt et al. (2011) report that the principles of the ecosystem approach underpin recent policies such as the European Water Framework Directive, the Baltic Sea Action Plan, and the Land Use Strategy for Scotland. Whilst, the Countryside Council for Wales, Forestry Commission Wales and the Environment Agency Wales have been merged to take a joined-up approach to the environment through the newly created 
Natural Resources Wales, a move underpinned by the principles of the ecosystem approach. Demonstration projects have also begun to develop, including Defra's Delivering Nature Services in Upland Landscapes, the Stirling Land Use Pilot, and the Celtic Seas Partnership. In each case, operationalising the ecosystem approach has been achieved differently, suggesting that there is currently no pre-defined process which constitutes 'taking an ecosystem approach'. Instead the ecosystem approach remains open for interpretation, an evolving framework of ideas (Secretariat of the CBD, 2000).

However, some similarities in approaches can be recognised and Potschin and Haines-Young (2013) and Holt et al. (2011) highlight that the operationalisation of the ecosystem approach, ecosystem service assessments and management has largely occurred through a habitats or a systems-based framework. Habitat-based frameworks focus on the biophysical components that dictate ecosystem functions and service delivery, such as biomes or ecotypes, whilst systems-based frameworks concentrate on structural and functional relationships and processes. Yet, the ecosystem approach is also about socio-ecological connections, the inclusion of people in ecosystems (Hancock, 2010; Hartje, 2003; Secretariat of the CBD, 2000).

Arguably, to be widely accepted and rolled out, any framework used to apply the ecosystem approach in land use planning needs to not only be environmentally coherent but also meaningful to local communities and government. Effectively, a socio-ecological framework is needed to bridge the divide between the scale and boundaries at which ecological and human systems operate. Based on this reasoning, place-based frameworks have also been suggested by Potschin and Haines-Young (2013) as a potential transboundary medium. The term place-based is used to refer to socially grounded frameworks which highlight the 
connections between people and the environment by 'looking at bundles of services across units that have a strong social relevance or resonance'. There has however been relatively limited exploration of place-based framework as mechanisms to operationalise the ecosystem approach, this paper examines the potential role of one place-based approach, landscape character assessment.

\section{Landscape Character Assessment as a Place-Based framework}

Landscape character assessment is one of the most prominent landscape assessment tools in the UK planning system. Swanwick and Land Use Consultants (2002:8) describe landscape character as the 'distinct and recognisable pattern of elements that occur consistently in particular types of landscape', and landscape character assessment, or LCA, as 'the process of identifying and describing variation in the character of the landscape' (Tudor, 2014:8). Landscape character is a result of the palimpsest of layers of the landscape (geology, geomorphology, archaeology, vegetation, agriculture) which together combine to produce distinctive landscapes elements. LCA is a systematic method of landscape evaluation based around identifying the pattern of elements which make an area unique, which is then mapped into character areas and types, with an accompanying description (Swanwick and Land Use Consultants, 2002). By exploring character the focus of LCA is on the integrated natural and cultural factors which have together influenced the evolution and composition of the landscape (Warnock and Griffiths, 2014). The key aspect of LCA is that it is designed to identify and communicate what makes a landscape distinctive for people, and is linked specifically to preserving the landscape elements that stakeholders value (Swanwick and Land Use Consultants, 2002; Tudor, 2014; Selman, 2012). 
Over the last 20 years, LCA has been applied to a variety of spatial problems, used in landscape strategies, landscape and visual impact assessments, spatial planning, and extended into a hierarchy through national, county, and local level assessments (Swanwick and Land Use Consultants, 2002; Warnock and Griffiths, 2014). LCA is embedded as a framework for the management of landscape change and has operated as the mainstay for contemporary UK landscape planning practices. The concept of character is also an important core planning principle in the National Planning Policy Framework (2011), and character is use to ensure that development and plans (such as neighbourhood plans) takes place with consideration of their wider surrounding. The application of LCA has also gained footholds in Europe, and alternative landscape evaluation approaches have developed with similar principles, such LANDMAP, which also seeks to map public perception of landscape (Scott, 2002).

The value of characterising the landscape is strongly linked to its ability to distil the complex concept of landscape into a manageable form. LCA is designed to act as an environmentally and socially coherent framework, which cuts across administrative boundaries and informs location sensitive planning and decision-making (Swanwick and Land Use Consultants, 2002; Tudor, 2014). The acknowledgement of the distinctive landscape elements which contribute to sense of identity, rather than quality, also classifies LCA firmly as a place-based evaluation tool. Furthermore, by taking into account geomorphological, biological, and cultural elements, LCA is a socio-ecological assessment, operating on the boundary between the societal concept of place and the ecological concepts of space.

\section{Linking Landscape, Landscape Character Assessment and the Ecosystem Approach}


On a conceptual level, the relationship between LCA and the ecosystem approach depends on the underlying relationship between the paradigms of landscape and of ecosystems. The extent to which these two paradigms overlap is a longstanding debate in the academic literature. Ecosystems are linked to organisms, populations, flows of energy, interrelationships and assemblages (Carmel and Naveh, 2002; Schaich et al. 2010), they are not spatially distinct but loosely defined and operate on a range of scales and organisational complexity (De Leo and Levin, 1997). Landscape is an equally nebulous concept. For some landscape is an ecological dimension or biophysical unit (Brunckhorst et al. 2006; Noss, 2001), a tract of interacting ecosystems and elements in a defined space (Forman and Gordon, 1986). For others, landscape is much more of a socio-ecological concept based on people's perceptions, lived experiences, aesthetics and emotions (Fairbrother, 1970, Meinig, 1979; Schaich et al. 2010), 'the product of natural and cultural influences which have been interwoven for thousands of years' (Carmel and Naveh, 2002:37). Therefore, the paradigms of landscape and ecosystems 'elucidate similarities as well as vast differences' (Carmel and Naveh, 2002:35).

The social and ecological connections of landscape have led to the promotion of landscapescale planning and governance as an integrative framework through which to bridge the divide between existing systems and ecosystems, and ensure the management of issues which considers the wider ecological and social context or setting (Selman, 2006; 2012). Landscape-scale planning is associated not only with taking a more holistic approach, but also the perception of landscape as a having scalar and spatial properties through which public policy and spatial planning can manage social and ecological issues in parallel (Selman, 2006; 2012; Swanwick, 2004; Warnock and Griffin, 2015). 
For the ecosystem approach, Vos and Meekes (1999) suggest that the holistic nature of landscape studies could foster the integration of disparate silos of planning and decision making, at various temporal and spatial scales. Not only is landscape considered an integrating concept, but there are also suggestions that the social and ecological dimensions of landscape mean it is potentially an optimum framing for the application of the ecosystem approach (Hartje et al. 2003; Muller et al. 2010; Ahern and Cole, 2012).

While social and environmental phenomena occur at a wide range of scales, society engages with environmental phenomena at a particular scale, that of landscape (Gobster et al. 2007:959)

By resolving the issues of integration and scale, landscape is seen by some as the solution to the challenge of operationalising the ecosystem approach. However, the different perceptions of landscape could closely affect the relationship between LCA and the ecosystem approach, allowing some authors use the term ecosystem and landscape interchangeably (e.g. de Groot, 2006; Noss, 2001) and others to consider landscape solely from a social perspective as a cultural and aesthetic element (e.g. Council for Europe, 2000; Muir, 1999).

Over the past decade it is evident that the paradigms of landscape and the ecosystem approach have increasingly been merged. Landscape has been described as a multifunctioning ecosystem (Potschin and Haines-Young, 2006), and a space-place network which provides ecosystem services (Matthews and Selman, 2006; Bolliger and Kienast, 2010). The term landscape services has even come into use in place of ecosystem services (de Groot, 2006; Herman et al. 2011), as a means to describe and understand the landscape processes and structures from which ecosystem services are derived (Jones et al. 2008). 
However, much of this discussion has, so far, been theoretical, and whether landscape can be used as a geographical unit and place-based framework for the ecosystem approach remains largely unproven (Schaich et al. 2010). Therefore, the socio-ecological nature of the landscape paradigm is potentially an attractive framework for operationalising the ecosystem approach, but also brings with it questions as individual perceptions of what constitute landscape can differ widely (Schaich et al. 2010).

Perceptions of landscape are likely to have a critical influence for LCA relevance for operationalising the ecosystems approach, as highlighted by Butler (2016) the process of characterisation entails the definition of landscape and consequently LCAs differ due to different perception of landscape. For LCA, the cultural dimension of the landscape paradigm has, so far, dominated its connection to ecosystem services. Character assessment, as a tool to capture what makes a landscape distinctive or unique, has been perceived and used as a data source or proxy for cultural ecosystem services such as sense of place (Potschins and Haines-Young, 2013). The focus on visual coherence, form or pattern in the landscape means that LCA is sometimes viewed as more of an aesthetic or cultural aspect, rather than as a place-based framework, which could limit its role in capturing the more fluid interactions which are key to the ecosystems approach (Natural England, 2009; Warnock and Griffiths, 2014; Butler, 2016). Yet, the potential for LCA to operate as a framework for the ecosystem approach, based on perceptions of landscape as form or surface, have also begun to be acknowledged, to some extent, by the UK ministry for the environment, DEFRA, which has opted to update the national character areas profiles for ecosystem services (Natural England, 2012; DEFRA, 2012).

In addition, to potential roles as a data source or spatial framework, there are also 
suggestions that LCA could also act as a delivery mechanism for the ecosystem approach, through the potential relationship between landscape character, pattern, structure, function and services (Termorshuizen and Opdam, 2009). Linking together landscape characteristics and functions, points to broader questions about the relationship between landscape aesthetics, and human and ecological systems and processes (Gobster, 2007), which could prove critical for making ecosystem services spatially explicit for ecosystem approach based decision-making (Willemen et al. 2008). LCA has already been applied to measure environmental change (e.g. Haines-Young et al. 2007; Countryside Agency, 2006), and to provide a spatial framework for the analysis of ecological structure (Kim \& Pauleit, 2007). Undeniably, there are increasingly efforts to quantify the relationship between landscape characteristics and their respective functions and services (Willemen et al. 2010; Muller et al. 2010). Although the creation of distinct character areas is beneficial for management there are acknowledged difficulties in reconciling character with highly mobile ecological processes (Julie Martin Associates and Swanwick, 2003). Therefore, whether LCA can provide a medium to address the mismatch between the biophysical scales at which ecosystem services are generated, social scales of beneficiaries, and the institutional scales at which stakeholders interact with them, remains unanswered (Hein et al. 2006; Luck et al. 2009).

\section{Research Aim}

Place-based approaches are one pathway to operationalise the ecosystem approach, a medium which could potentially bridge the boundaries between ecosystem functions, cultural concepts of place and pre-existing bureaucratic borders. However, research on place-based approaches remains limited. In the UK, LCA is a place-based approach to landscape planning and management, underpinned by a well-established methodology 
(Swanwick and Land Use Consultants, 2002). National guidance on the application of LCA suggests that one benefit may be its ability to integrate social, cultural and natural constituents, and provide an understanding of how a place is experienced perceived and value by people (Tudor, 2014). The aim of this research is to further investigate the relationship LCA and the ecosystem approach, to better establish the potential of placebased approaches in operationalising the ecosystem approach.

\section{Research Methodology}

The methodological strategy was based on undertaking a qualitative appraisal of the potential roles of LCA in the ecosystem approach. To this end, the study was based on a series of semi-structured interviews and case studies. A total of 15 interviews were undertaken with participants who work with LCA and are also seeking to apply the ecosystem approach in the UK, including practitioners, such as planners, protected area officers and landscape officers from Areas of Outstanding Natural Beauty (AONBs) and National Parks, along with experts, such as academics and policy makers. The interviews and analysis were framed around investigating the theoretical relationship between landscape, LCA and the ecosystem approach. Further questions focused on exploring the potential role of LCA in the application of the ecosystem approach, and the extent to which these two approaches could potentially connect. Derived from the interviews, four case studies then provide some emerging practical examples where LCA and the ecosystem approach have directly, or indirectly, been linked.

\section{Empirical Results and Discussion}

\section{Landscape and the Ecosystem Approach}

Collectively participants recognised that landscape and the ecosystem approach as highly 
similar concepts, even describing them as 'one in the same', on the basis that landscape seems to meet 'all', 'almost all', or ' $80 \%$ ', of the principles of the ecosystem approach. This similarity supports ideas that these terms can be used interchangeably (e.g. de Groot, 2006; Noss, 2001), and highlights that, theoretically, these concepts were considered easy to weave together.

In the ecosystem approach people tend to think of landscape as just fitting in as a cultural ecosystem service, but there is also a natural process and context side to landscape (Policy Maker).

However, the concurrence between these two concepts was also portrayed as conditional. A link which was principally grounded on the perspective of landscape as a multifunctional concept: an ecological as well as a cultural scale. Different perceptions of landscape were thought to have the potential to produce different interpretations of the relationship between landscape and the ecosystem approach.

Yet, many interviewees did not view landscape's strong cultural association as a significant point of contention.

Landscape's great advantage, in relation to the ecosystem approach, is as a holistic element that can encompass everything (National Park Landscape Officer).

Instead participants recognised the holistic nature of the landscape paradigm as a direct means of bridging ecosystems functions with their cultural or social context and beneficiaries, echoing de Groot (2006) and Carmel and Naveh (2002). The strong cultural connection could typecast landscape as solely a proxy for cultural ecosystem services, but this connection was instead seen as a core advantage and justification for a more significant role of landscape as a meaningful socio-cultural framework to help people relate to 
ecosystem services. These perspectives clearly reflect the value of place-based frameworks outlined by Potschin and Haines-Young (2013). The holistic nature of landscape, although an advantage for the ecosystem approach, was however also recognised as potentially at odds with the highly reductionist concept of ecosystem services.

\section{Landscape Character Assessment and the Ecosystem Approach}

Participants were then asked to consider the potential connections between LCA and the ecosystem approach. Combining these two concepts was initially recognised as 'potentially powerful' (AONB Officer). Although, some references were made to the use of character as a proxy for cultural ecosystem services, the dominant link made was based on the use of LCA as a spatial framework for ecosystem services assessment and ecosystem based decision making. However, the reasoning behind for the role varied considerably.

Academics and experts emphasised the synergies between the two concepts based on the holistic and contextual aspects of landscape captured by LCA, and the potential relationship between landscape, landscape character, ecosystem functions and services. Whereas, practitioners emphasised ideas of convenience and efficiency, stating that the use of LCA as a spatial framework could help to avoid establishing more boundaries and commissioning new frameworks.

For me it's practical to use landscape for the application of the ecosystem approach, as we have a character assessment in the area and understand how works. It will be interesting to see how closely they matchup (Conservation Officer, AONB).

This practical nature of LCA was often referred to, as practitioners could envisage landscape character areas being used to provide 'digestible' information on ecosystem services to inform responses to planning applications, and experts referred to LCA as 'breaking down 
the landscape into manageable pieces'.

However, the idea that landscape character could provide a spatial framework for the ecosystem approach was by no means universal. One practitioner stated that:

In practice, landscape character assessment and the ecosystem approach will not line up easily, because of the large scale and cross boundary way that some ecosystem services are distributed (Landscape Officer, Local Authority).

Clearly there are questions as to whether place-based landscape character areas would work as an ecological framework. Alternative, and equally viable, frameworks, such as systems based catchments, were also suggested. Yet, catchments were not recognised by interviewees as a holistic framework, but one that could only provide a limited perspective. Some participants considered frameworks to be a flexible choice, which should be made depending on audience, whilst, other practitioners were very keen on hanging everything on one framework. Choice of spatial framework will clearly be significant, influenced by the specific aspects and issues unique to an area, and how well that framework is currently understood. The strong focus on LCA as a spatial framework supports use beyond its current conceptualisation as a proxy for cultural ecosystem services. However, amongst the supportive opinions of participants there is also apprehension and indications of potential limitations around the degree to which LCA could operate as a genuine spatial framework, one which is ecologically relevant rather than simply a convenient.

\section{Landscape Character Assessment as a Spatial Framework}

Undoubtedly, one of the most significant issues in implementing the ecosystem approach is addressing the mismatch between the scales and boundaries of ecosystems and that of man-made administrative areas (e.g. Hancock, 2010; Brunckhorst et al. 2006). Theoretically, 
LCA should be both socially and ecologically relevant. Just over half of participants thought that the boundaries and scales of landscape character areas were ecologically relevant, and that landscape 'character types overlap well with the ecosystems in the area'. One practitioner stated that in their area:

The character types in the AONB are based on the broad ecosystem in the area e.g. moorland plateaus. So yes looking at the character types they are ecologically relevant (Conservation Officer, AONB).

Ecosystems were often expressed by interviewees as sitting within the landscape-scale, suggesting that there is no great divide between cultural, social and ecological aspects in landscapes.

The idea of the ecosystem approach as a multi-scalar approach was also prevalent in the interview responses, with academics and experts highlight that the hierarchal nature of LCA, stretching from national to local scales, should help to capture multi-scale ecosystems and their services, from water supply to as pollination. However, the level of correspondence between character areas and ecosystem was also critiqued by one landscape officer as more 'incidental than by design'. Certainly, the extent to which character areas, which are derived from a wide range of factors, are relevant for ecosystem management is somewhat unspecified. Ecosystems are notoriously difficult to define, and participants emphasised that LCA boundaries and areas do not fit well with ecosystems. Although, character areas were thought of by some participants as having zones and transitions, reflecting ideas of fuzzy boundaries, the focus in the ecosystem approach is firmly on inter-relationships and networks, aspects which are not traditionally captured by LCA framework which provides a snapshot of the landscape and therefore a presents a static viewpoint of the landscape. 
Consequently, the extent to which character areas may be ecologically relevant could be limited.

\section{Landscape Character, Landscape Function and the Ecosystem Approach}

Both practitioners and academics also identified potential connections between changing and enhancing landscape character and the management and provision of ecosystem services, as suggested by Termorshuizen and Opdam (2009).

Landscape character assessment is based on landscape pattern and aesthetics to a certain degree, but this is also the consequence of underlying ecosystem services and functions coming through those land-use patterns, landscapes and land-forms (Policy Maker)

Through the link between landscape character and landscape ecology concepts such as landscape pattern and functionality, participants recognised that landscape character could be connected into the operationalisation of the ecosystem approach and used to manage ecosystem services.

Landscape function hasn't been particularly prominent in the landscape character assessment methodology, however the function of landscape features is a critical way that landscape character assessment could contribute to the ecosystem approach (Policy Maker).

However, several participants also stressed that the extent to which the idea of landscape function is utilised with LCA is debatable. Currently, LCA tells you about the way a landscape is structured, identifies character areas and types, but it is a static assessment of the landscape and often does not take the next step to think about landscape functions 
and interactions.

One possible route to enhancing consideration of landscape function in LCA is through 'landscape condition'. The measure of landscape condition is based upon judgements about the physical state of the landscape, and about its intactness, from visual, functional and ecological perspectives' (Swanwick and Land Use Consultants, 2002). Some methodological approaches taken in current practice recognises that landscape condition has a visual dimension, reflecting the degree to which the landscape appears visually unified, and a functional dimension, reflecting the degree to which the landscape functions as a selfsustaining resource (Griffiths and Warnock, 2016). The 'functional integrity' of the landscape is said to reflect the condition of the habitat network (degree of fragmentation/intensity of land-use) and the survival of the cultural pattern (Griffiths and Warnock, 2016). The ecosystem approach would assess 'functional integrity' by exploring the delivery of ecosystem services, and in this way may provide a valuable complement to the LCA by clarifying the key dimensions of landscape condition.

Although landscape function could be critical, currently function is not particularly prominent in the LCA methodology, at best an inherent rather than explicit element. Furthermore, landscape function may not be the simplest route to assign ecosystem services to landscape character, as only some spatial functions relate to observable landscape features (Willemen et al. 2008). The current understanding of the relationship between landscape character, functionality and ecosystems services is also incomplete (e.g. Ren et al. 2013), if LCA is to be applied to manage ecosystem services the link between place-based character areas and more ecologically-based landscape patterns and functions requires further development. However, these ideas point to a potentially deeper relationship 
between landscape character and the ecosystem approach, which could be critical for uptake and potentially enhance LCA as a tool (e.g. if we could find out the characteristics of high carbon fixing landscape and replicate these), but currently remains an undeveloped area for future research.

\section{Emerging practice: Case studies of Landscape Character Assessment and the Ecosystem}

\section{Approach in Action}

Through the interviews four case studies were identified which illustrated early attempts to, directly and indirectly, use the ecosystem approach and LCA together.

$>$ The Peak District National Park Landscape Strategy and Action Plan (2009)

The South Pennines National Character Area Profile (2012)

Medway Council Landscape Character Assessment (2011)

Wye Valley Area of Outstanding Natural Beauty Ecosystem Services Report (2011)

Each case used LCA to apply the ecosystem approach to a variable extent, based on very different approaches, and at a range of spatial scales. In the South Pennines the National Character Area Profile has been used as a framework through which to attribute ecosystem services to landscape characteristics, relatively descriptively, and indicates possible routes for the enhancement of ecosystem services. While, the Peak District National Park Landscape Strategy and Action Plan has not attempted to allocate ecosystem services to landscape character areas, but instead identified that landscape planning and character areas could be used to indirectly manage, enhance or change ecosystem services, such as climate change resilience. Landscape, rather than systems or habitats, was considered the most relevant framework for implementing the ecosystem approach. In the Medway, the connection between LCA and the provision of ecosystem services is highlighted but the link 
appears to be relatively limited, descriptive rather than functional. Finally, in the Wye Valley the information in the LCA has been utilised as a data source for an ecosystem services assessment, with the two reports following the same basic framework.

One of the key points which can be drawn collectively from the case studies is the general appreciation that if you change the landscape character you will change the ecosystem service provision. This links to the work of Wood and Handley (2001) who highlighted that degraded landscape character and condition can be linked to a loss of function (obsolescence), or a mismatch between the type or intensity of land-use and the character and capacity of the receiving landscape (dysfunction). This commonality in the management of change through landscape character gives weight to the idea of using LCA to implement the ecosystem approach. However, the extent to which this relationship is exploited clearly varies from case study to case study. In some cases, the incorporation of ecosystem services into LCA is relatively superficial, LCA is largely being used as a framework to identify features of the landscape which related, for presentational purposes, to ecosystem services. Whereas in other cases LCA has a much more active role and character areas and types are recognised as units through which ecosystem services can be enhanced and linked into landscape management policies.

The range of case studies is limited but it clearly demonstrates the flexibility of LCA tool to facilitate the ecosystem approach in different situations and to different extents. The case studies also illustrate the potential of LCA to operate along a spatial hierarchy of scales. However, exactly how much influence LCA has in planning, policy and decision making remains uncertain and is a clear question for further research. More recent experiences have confirmed the early promises of these case studies. Warwickshire county council have 
recently developed a pilot project to link ecosystem services in LCA, and reportedly similar work is occurring in the South Downs. While Land Use Consultants are exploring prospective new approaches to LCA in Dorset which include landscape change and ecosystem services strategies.

\section{Conclusion}

This study has explored the potential role of one place-based approach, LCA, to help operationalise the ecosystem approach in planning, management and decision making. Bridging the divide between the scale and boundaries at which ecological and social systems operate at, in a medium which is meaningful to local communities and government, is considered vital to ensuring that the widespread acceptance and uptake of the ecosystem approach. Landscape was clearly acknowledged by interviewees as a medium to bridge the divide between the ecological and cultural context to help people relate to ecosystem services, and LCA considered relevant to the application of the ecosystem approach as a data source, proxy for sense of place, and significantly as a spatial framework for the management of ecosystem services. The relevance of LCA for the application of the ecosystem approach was rooted in the holistic and multifunctional nature of the landscape concept.

Using LCA as a spatial framework to apply the ecosystem approach was based, for some interviewees, on the perceived overlap between landscape and ecosystem, and for others as a practical means to avoid establishing new frameworks. The key benefits of the LCA approach were linked to the provision of manageable information on ecosystem services at a landscape scale, thereby placing information on ecosystem services into a relevant context for local communities and governance. However, the ecological relevance of the 
LCA framework was a subject of debate, and considered by some more incidental than inherent. Moreover, there were questions as to whether the LCA would be an appropriate framework to communicate the ecosystems approach to all stakeholders.

The prospective connections between landscape aesthetics and character, landscape pattern and functionality, and ecosystem functions and services, were seen as a potentially powerful link between place-based LCA and the ecosystem approach. Through these connections it was envisaged that character areas could be used actively manage ecosystem services and operationalise the ecosystem approach. An important finding is also that the ecosystem approach may in turn complement LCA by clarifying the functional dimension of landscape condition and prioritising an effective framework for landscape planning and management. The findings point to a wider debate about the overlap between our sense of place, aesthetics and the ecological spaces from which we generate ecosystem services, and links into Selman's (2012) concept of the ecological aesthetic. However, the assessment of landscape function through condition was the key connection between landscape character and ecosystem services, but has historically been a critically under-utilised component of LCA.

To implement the ecosystems approach through LCA more needs to be done to explicitly link the character of a place to its function and services. LCA could potentially be used in two ways to help operationalise the ecosystem at a local level (1) LCA could be used to provide an overview of the characteristics, functions and services of a place and operate as a pathway for more detailed assessment, (2) if the relationship between ecosystem services, landscape function and character could be further developed then an LCA (plus) 
approach could be developed, which from the outset could provide an socio-ecological framework for the ecosystem approach.

Acknowledgements: Our thanks go to the interviewees and to Jonathan Porter. This research was completed as part of a master's dissertation at the University of Manchester.

\section{References}

Ahern, K., and Cole, L., 2012, Landscape Scale - towards and integrated approach, ECOS, 33,314, 612.

Bolliger, J., and Kienast, F., 2010, Landscape Functions in a Changing Environment, Landscape Online, 22, 773-389.

Brunckhorst, D., Reeve, I., and Coop, P., 2006, Eco-Civic Optimisation: A Nested Framework for Planning and Managing Landscapes, Landscape and Urban Planning, 75, 3-4, 265-281.

Butler, A., 2016, Dynamics of integrating landscape values in landscape character assessment: the hidden dominance of the objective outsider, Landscape Research, 41, 2, 239-252.

Carmel, Y., and Naveh, Z., 2002, The paradigm of landscape and the paradigm of ecosystems Implication for land planning and management in the Mediterranean Region, Journal of Mediterranean Ecology, 3, 2-3, 35-46.

Cumming, G. S., Cumming, D. H. M., and Redman, C. L., 2006, Scale mismatches in social-ecological systems: causes, consequences, and solutions, Ecology and Society, 11, 1, 14.

Secretariat of the Convention on Biological Diversity, 2000, COP 5 Decision V/6, The ecosystem approach, Secretariat of the Convention on Biological Diversity, Montreal.

Council for Europe, 2000, European Landscape Convention, EU. 
Countryside Agency, 2006, Countryside Quality Counts - Tracking Change in the English Countryside, Countryside Agency, DEFRA, Environment Agency.

Daily, G.C., Polansky, S., Goldstein, J., et al., 2009, Ecosystem services in decision making: time to deliver, Frontiers in Ecology, 7, 1, 21-28.

Daily, G.C., and Matson, P.A., 2008, Ecosystem Services From Theory to Implementation, Proceedings of the National Academy of Sciences, 105, 9455-9456.

DEFRA (Department for Environment, Food and Rural Affairs), 2011, Natural Environment White Paper (NEWP), A Natural Choice, DEFRA, HMSO, London.

De Groot, R.S., 2006, Function-Analysis and Valuation as a Tool to Assess Land Use Conflicts in Planning for Sustainable, Multi-Functional Landscapes, Landscape and Urban Planning, 75, $175-186$.

De Groot, R.S., Alkemade, R., Braat, L., et al, 2010, Challenges in Integrating the Concept of Ecosystem Services and Values In Landscape Planning, Management And Decision Making, Ecological Complexity, 7, 260-272.

De Leo, G., and Levin, S., 1997, The Multifaceted Aspects of Ecosystem Integrity, Conservation Ecology, 1, 1, 3, 1-16.

Fairbrother, N., 1970, New Lives, New Landscapes, Pelican, London.

Forman, R., and Godron, M., 1986, Landscape Ecology, John Wiley \& Sons, New York.

Gobster, P.H., Nassauer, J.I., Daniel, T.C., et al., 2007, The Shared Landscape: What Does Aesthetics Have to Do With Ecology? Landscape Ecology, 22, 959-972. 
Griffiths, G., and Warnock, S., 2016, Character and Condition: The role of landscape character assessment for the future of landscapes, Landscape Characterisation: Methods and Application in Landscape Ecology, IALE16 Conference, 7-9 September 2016, University of Reading.

Haines-Young, R., and Potschin, M., 2007, The Ecosystem Concept and the Identification of Ecosystem Goods and Services in the English Policy Context, Review paper to DEFRA, NRO107.

Haines-Young, R., Langanke, T., and Potschin, M., 2007 Landscape Character as a framework for the assessment of environmental change, In: Petrosillo I., et al. (eds.): Use of Landscape Sciences for the Assessment of Environmental Security, Springer, 165-174.

Hancock, J., 2010, The Case for an Ecosystem Service Approach to Decision Making: An Overview, Bioscience Horizons, 3, 2, 188-196.

Hartje, V., Klaphake, A., Schliep, R., 2003, The International Debate on the Ecosystem Approach: Critical Review, International Actors, Obstacles and Challenges, BfN Skripten (German Federal Agency for Nature Conservation), Bonn.

Hein, L., van Koppen, K., de Groot, R.S., and van Lerland, E.C., 2006, Spatial Scales, Stakeholders and the Valuation of Ecosystem Services, Ecological Economics, 57, 209-228.

Herman, A., Schleifer, A., and Wrbka, T., 2011, The Concept of Ecosystem Services Regarding Landscape Research: A Review, Living Reviews in Landscape Research, 5, 1.

Holt, A.R., Godbold, J.A., White, P.C.L., et al., 2011, Mismatches between legislative frameworks and benefits restrict the implementation of the Ecosystem Approach in coastal environments, Marine Ecology Progress Series, 434: 213-228.

Hughes, R., The evolution of landscape character assessment, Landscape, The Journal of the 
Landscape Institute, Landscape Autumn 2014, [ONLINE] Available at: http://www.landscapethejournal.org/The-evolution-of-Landscape-Character-Assessment [Accessed on 2nd September 2016].

Jones, K.B., Krauze, K., Müller, F., et al., 2008, Landscape Approaches To Assess Environmental Security: Summary, Conclusions, And Recommendations, In Petrosillo, et al. (eds), Use of Landscape Sciences For The Assessment Of Environmental Security, NATO Science For Peace And Security Series - C, Environmental Security, Dordrecht, Springer, 475-486.

Julie Martin Associates., and Swanwick, C., 2003, Overview of Scotland's National Programme of Landscape Character Assessment, Scottish Natural Heritage, Report F03 AA307.

Kim, K.H., and Pauleit, S., 2007, Landscape Character, Biodiversity and Land Use Planning: The Case of Kwangju City Region, South Korea, Land Use Policy, 24, 1, 264-274.

Luck, G.W., Harrington. R., Harrison, P.A., et al., 2009, Quantifying the Contribution of Organisms to the Provision of Ecosystem Services, Bioscience, 59, 223-235.

Maltby, E., 2000, Ecosystem Approach: From Principle to Practice, Ecosystem Service and Sustainable Watershed Management in North China Conference, Beijing, August 23 - 25, 2000.

Matthews, R., and Selman, P., 2006, Landscape as a Focus For Integrating Human And Environmental Processes, Journal of Agricultural Economics, 57, 199-212.

Meinig, D.W., 1979, The Interpretation of the Ordinary Landscape, Oxford University Press, Oxford.

Muir, R., 1999, Approaches to Landscape, Macmillan Press, London.

Muller, F., de Groot, R., and Willemen, L., 2010, Ecosystem Services at The Landscape Scale: The Need For Integrative Approaches, Landscape Online, 23, 1-11. 
Natural England, 2009, Experiencing Landscape: Capturing The Cultural Services and Experiential Qualities Of Landscape, NE Commission Report NECR024.

Noss, R. F., 2001, Maintaining ecological integrity of landscapes and ecoregions, In Pimentel, D., Westra, L., and Noss, R. F (eds), Ecological integrity: integrating environment, conservation, and health. Island Press, Washington, D.C, 191-208.

Potschin, M., and Haines-Young, R., 2006, Rio+10 Sustainability science and landscape ecology, Landscape and Urban Planning, 75, 3-4, 162-174.

Potschin, M., and Haines-Young, R., 2013, Landscape, Sustainability and the Place Based analysis of Ecosystem Services, Landscape Ecology, 28, 1053-1065.

Potschin, M., Haines-Young, R. and R. Fish, 2011, Embedding an Ecosystem Approach in Decision Making: Measuring the Added Value, Overview Report, Defra Project Code: NR0135. CEM Report No 18, 53.

Ren, Y., Wei, X., Wang, D., et al., 2013, Linking landscape patterns with ecological functions: A case study examining the interactions between landscape heterogeneity and carbon stock of urban forests in Xiamen, China, Forest Ecology and Management, 293, 122-131.

RSPB (Royal Society for the Protection of Birds), 2009, Naturally At Your Service: Why It Pays To Invest In Nature, RSPB, Sandy.

Scott, A., 2002, Assessin public perception of landscape: the LANDMAP experience, Landscape Research, 27, 3, 271-295.

Schaich, H., Bieling, C., and Plieninger, T., 2010, Linking Ecosystem Services with Cultural Landscape Research, GAIA, 19/4, 269-277. 
Selman, P., 2006, Planning at the Landscape Scale, RTPI series, Routledge, London.

Selman, P., 2012, Sustainable Landscape Planning: The Reconnection Agenda, Routledge, Abingdon.

Smith, R.D., and Maltby, E., 2003, Using the Ecosystem Approach to Implement the Convention on Biological Diversity: Key Issues and Case Studies, Ecosystems Management Series, 2, IUCN, Gland.

Swanwick, C., 2002, Landscape Character Assessment, Topic Paper 1: Recent practice and the evolution of Landscape Character Assessment, Report for the Countryside Agency.

Swanwick, C., and Land Use Consultants, 2002, Landscape Character Assessment - Guidance for England and Scotland, CAX 84, Countryside Agency, Cheltenham and Scottish Natural Heritage, Edinburgh.

Termorshuizen, J.W., and Opdam, P., 2009, Landscape Services as a Bridge Between Landscape Ecology and Sustainable Development, Landscape Ecology, 24, 1037-1052.

Tudor, C., 2014, An Approach to Landscape Character Assessment, Natural England.

Vos, W., and Meekes, H., 1999, Trends in European cultural landscape development: perspectives for a sustainable future, Landscape and Urban Planning, 46, 1-3, 3-14.

Warnock, S., and Griffiths, G., 2014, Landscape Characterisation: The Living Landscapes Approach in the UK, Landscape Research, 40, 3, 261-278.

Willemen, L., Verberg, P.H., Hein, L., And Van Mensvoort, E.F., 2008, Spatial Characterisation of Landscape Function, Landscape and Urban Planning, 88, 34-43.

Wood, R., and Handley, J., 2001, Landscape dynamics and the management of change, Landscape Research, 26, 1, 45-54. 
Figure 1. The Ecosystems Approach (Figure produced by the Ecosystems Knowledge Network)

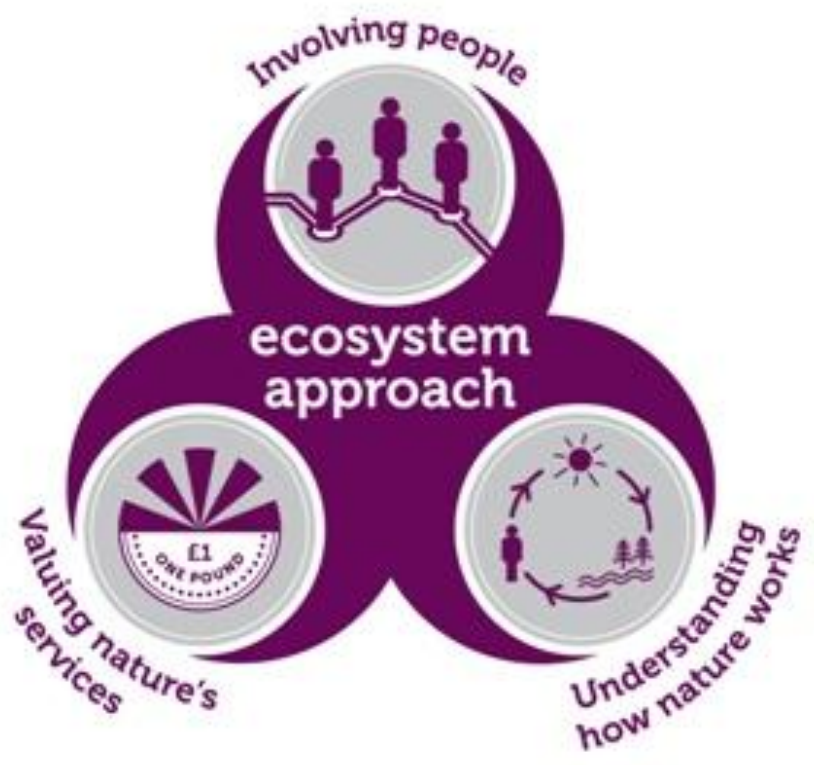

Figure 2. Glossary of key terms

\section{GLOSSARY}

Ecosystems: A dynamic complex of plant, animal and micro-organism communities and their non-living environment interacting as a functional unit.

Ecosystem approach: A strategy for the integrated management of land, water and living resources that promotes conservation and sustainable use in an equitable way.

Ecosystem services: The direct and indirect contributions of ecosystems to human well-being and society.

Ecosystem functions: The biological, geochemical and physical processes and components that take place or occur within an ecosystem.

Landscape character: A distinct, recognisable and consistent pattern of elements in the landscape that makes one landscape different from another, rather than better or worse.

Landscape services: The direct and indirect contributions that landscapes provide to human well-being and society, as well as aesthetic qualities.

Landscape function: The capacity or potential of the landscape to provide services. 
Figure 2. The Landscape Wheel (Figure produced by the Swanwick \& Land Use Consultants 2002)

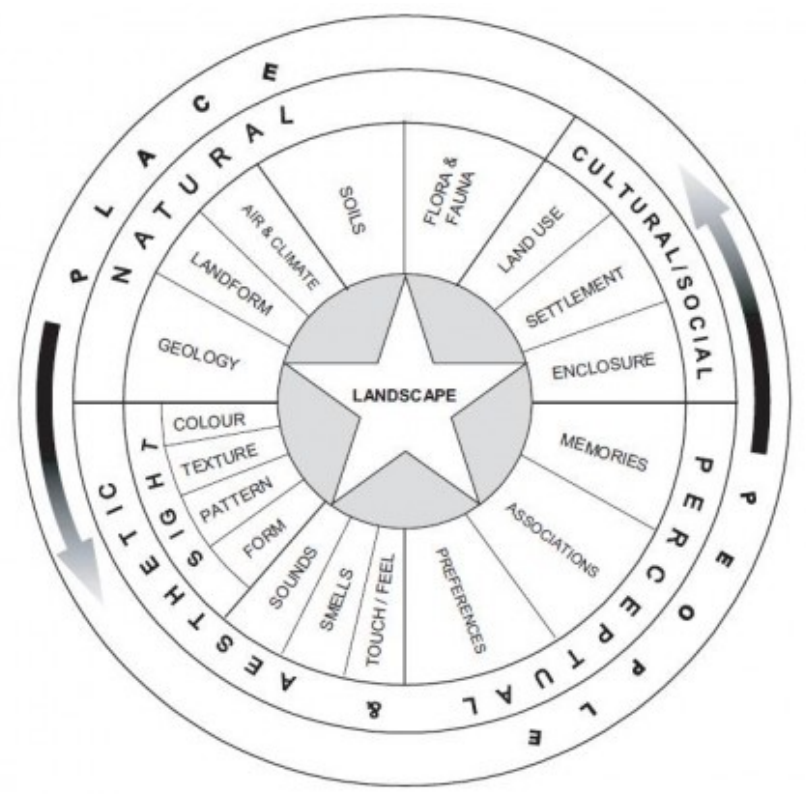

